\title{
Las lenguas y los lenguas: notas sobre la experiencia americana de la traducción
}

\author{
DÁMASO LÓPEZ GARCÍA \\ Universidad Complutense de Madrid \\ dlopez@ucm.es
}

Recibido: 2 de diciembre de 2012

Aceptado: 27 de febrero de 2013

\section{RESUMEN}

La importancia de la traducción en el proceso de descubrimiento y dominio de América no puede subestimarse. Dos elementos condicionan los procesos de traducción, por una parte que los soldados tienen necesidades muy concretas ligadas a la vida cotidiana y a los hechos de armas y carecen de conocimientos que les permitan entender los hechos de los que son testigos, mientras que, por otra parte, los frailes y religiosos en general traían ideas preconcebidas sobre América que necesariamente deformaban la percepción de los hechos y dejaron huella en las ideas sobre la historia de América.

Palabras clave: Lengua, América, traducción, lenguas americanas, españoles en América.

Lenguas and Languages: Notes on the American Experience of Translation

\begin{abstract}
The importance of the translation process during the period of the discovery and conquest of America cannot be underestimated. Two major considerations emerge as relevant: Spanish soldiers present there usually had very few concrete needs beyond those associated with daily life and the requirements of warfare, and they mostly lacked the knowledge necessary to understand the events that were taking place before their eyes; on the other hand, Spanish clergymen and friars had preconceived ideas about America that significantly altered their perception of facts and left their imprint on the perception of the history of America.
\end{abstract}

Keywords: Language, America, lengua, translation, American languages, Spaniards in America.

Sumario: 1. Historia sumaria de los contactos entre lenguas en el mundo moderno. 2. Prejuicios de los españoles durante los primeros contactos con los pueblos americanos. 3. Pre- 
juicios de los nativos a la llegada de los españoles a América. 4. Idea de los españoles acerca del origen de los pueblos americanos. 5. Los pueblos americanos y el pueblo judío.

Probablemente la experiencia del primer contacto entre las lenguas americanas y la lengua española, la portuguesa y, quizá, en menor medida, la inglesa, sea uno de los fenómenos lingüísticos, de relación entre las lenguas, más significativos del mundo moderno. El fenómeno puede abordarse desde muchos puntos de vista, pues reclama la atención de filósofos del lenguaje, de historiadores, de historiadores del pensamiento, de historiadores de la lengua o de la cultura, de antropólogos, de sociólogos, de sociolingüistas. En fin, pocas disciplinas, artes, técnicas o tecnologías dejarán de haberse visto influidas por la inesperada relación entre un grupo de lenguas, señaladamente, el español, el francés, el inglés y el portugués, ante el conjunto de las lenguas amerindias. Hace singular el hecho el que sea este el primer fenómeno de esta escala, escala mundial, en el mundo post-medieval, en el mundo moderno. El siglo XVII, el siglo XVIII y el siglo XIX también fueron siglos relevantes en lo que se refiere al contacto entre lenguas, en América, en África o en Asia. En África, por ejemplo, las lenguas que tuvieron mayor protagonismo fueron el francés, el inglés y el portugués; mientras que en Asia el protagonista fue, prácticamente, solo el inglés, con una presencia declinante o residual del español (Filipinas), del francés (la Indochina francesa, Pondicherry, etc.) y del portugués (Macao, Timor, etc.). Los siglos posteriores a la llegada de españoles y portugueses a América, sin embargo, ya partían de un conocimiento nuevo, el que proporcionó el hecho de que finalmente ya se conocía todo el dominio de la geografía del mundo, ya se conocía el mapamundi. Pero durante el siglo XVI el conocimiento hubo de adaptarse muy rápidamente a dos mundos nuevos: al Nuevo Mundo, el de América, y al propio mundo viejo, Europa, al que también habían hecho nuevo en cierta medida los descubrimientos de los navegantes.

La importancia de la experiencia de aquellos contactos solo pudo establecerse tardíamente, pues, durante un tiempo, la incertidumbre en torno a los hechos descritos, los contactos entre las lenguas, no permitió conocer muy bien la extensión del fenómeno ni su significado. Los primeros españoles que pusieron el pie en el continente americano eran de forma mayoritaria soldados. Aquellos soldados no estaban preparados para enfrentarse con sutilezas de la lengua ni siquiera parecía que les interesaran especialmente los fenómenos de la comunicación, a no ser que se tratase de los asuntos más apremiantes de la comunicación diaria. En cuanto se abandonaba ese terreno seguro, las conjeturas y las conclusiones adquirían toda clase de representación fantástica. En aquellas circunstancias, la formación de un cuerpo de intérpretes, los lenguas, era imprescindible, por razones de índole estratégica; sin los lenguas, la penetración española, su conocimiento del presunto enemigo, de los recursos y capacidad de este, habría sido imposible. No es sorprendente que la Malinche fuera uno de los personajes mayores de los episodios de la presencia española en tierras de México. Ningún autor deja de señalar que el papel de la Malinche no fue el de una simple intérprete: 
Está claro que de no haber mediado ella [la Malinche], Cortés no habría podido poner en práctica su argucia para empujar a los totonacas a sacudirse el yugo de Motecuhzoma y, al no lograrse ese primer paso, los siguientes no se habrían dado. No se hubiera efectuado la entrada pacífica en Tenochtitlan, y queda descartada la prisión de Motecuhzoma. En ese caso, hubieran tenido que abrirse paso combatiendo desde las mismas playas. Lo probable es que la penetración se convirtiese en un proceso muy lento, a la manera de lo ocurrido en Norteamérica. La actuación de esa mujer no fue la de una máquina de traducir que, de manera mecánica, vertiera al náhuatl los mensajes que le daban. Fue trasladadora de culturas. Puede imaginársele captando el misterio de un dios muerto, clavado a un madero, pero que resucitó y vive, amén del dogma de la Trinidad, buscando las palabras adecuadas para realizar el traslado a la mentalidad indígena. Y al parecer no lo habría hecho tan mal. Por ello, no resulta exagerado decir que fue la llave que abrió las puertas de México. Pieza clave para la Conquista, y que, en su día, fue altamente respetada por los caciques, al grado de que Bernal dice que ésos, al no poder pronunciar el nombre de Cortés, por no existir la letra erre en la lengua náhuatl, lo hacían llamándolo Malinche. Esto es, «el capitán que acompaña a la señora Malintzin; y también se le quedó este nombre a un Juan Pérez de Artiaga, vecino de la Puebla, por causa que siempre andaba con doña Marina y con Jerónimo de Aguilar aprendiendo la lengua, y a esta causa le llamaban Juan Pérez Malinche» ${ }^{1}$.

Es evidente que los contactos entre los soldados españoles y los nativos americanos tuvieron que llevarse a término en condiciones difíciles, condiciones que dieron lugar a toda clase de equívocos. Los lenguas eran determinantes. Fueron la llave que abrió las puertas del imperio azteca. Pero formar un buen traductor no era cosa sencilla. Contar con su fidelidad era asunto aún más complejo y delicado. Los intérpretes, a su vez, podían ser indígenas, la Malinche, «Julianillo» o «el indio Francisco», de Bernal Díaz del Castillo; pero podían ser españoles que hubieran aprendido la lengua correspondiente, como Jerónimo de Aguilar, conocedor de la lengua maya, quien trabajó conjuntamente con la Malinche; como el paje Ortega, es decir, Orteguilla, español que sirvió de intérprete, informante y compañero de Moctezuma.

La compleja organización política, económica y militar del imperio azteca obligó a Cortés, que se planteó (cosa increíble) conquistar ese lugar, a buscar información, a dar información, a pactar, buscar aliados. Y para todo esto necesitaba hablar y escuchar. Es lógico, por lo tanto, que apenas desembarcado en Veracruz, buscara intérpretes. Así hicieron su aparición en la historia de América, los intérpretes de verdad, los que sabían las lenguas del conquistador y las de los que serían conquistados. Y estos intermediarios verbales dieron a Cortés mucha más fuerza que los ejércitos de tlaxcaltecas y otros aliados con los que, finalmente, conquistó ese enorme territorio. Si se observa con atención, el famoso conquistador no tenía más poder real que una verborrea, dicen, imparable. Y para traducirla no le era suficiente con un intérprete; utilizó tres: Aguilar, doña Marina o Malinche y

\footnotetext{
${ }^{1}$ En nota final, el autor, Miralles Ostos (2010: 429-430), atribuye las palabras entrecomilladas a Bernal Díaz del Castillo.
} 
Orteguita. Cortés le hablaba a Aguilar en castellano; Aguilar, que había vivido cautivo con los mayas ocho años y sabía bastante bien esa lengua, traducía a la Malinche que hablaba maya y náhualt ; doña Marina se dirigía a los interlocutores aztecas en náhualt; Orteguita, finalmente, un muchachito mexica al que le habían enseñado castellano, verificaba que lo que se decía era lo que quería decir y escuchar Cortés ${ }^{2}$.

La penetración española habría sido muy diferente si no se hubiera contado con el trabajo, más o menos improvisado, mejor o peor llevado a cabo, de quienes tomaban sobre sí la tarea de la intermediación lingüística. Probablemente los estudiosos de la traducción exageran un poco el poder de las artes de los intérpretes. No se sabe si, sin contar con ellos, no habría habido penetración española en, póngase por caso, México. La virtud de ese poder de mediación se resume mediante una conjetura incomprobable, aunque, sin duda, fue grande la importancia de intérpretes, lenguas, y traductores. Da una idea de esta importancia el hecho de que buena parte de los cronistas se sienta frustrada cuando no sabe expresar qué ocurre, qué ve o qué se le dice, pero también son conscientes los cronistas de la trascendencia de la traducción cuando el mismo acto de traducir, de interpretar lo que unos y otros dicen, es un asunto recurrente en las páginas de estos autores. Pocos autores hay que no brinden al lector una antología de hechos felices o, con más frecuencia, desafortunados relativos a los procesos de interpretación.

El anecdotario de las dificultades de los soldados españoles es inacabable. Bernal Díaz del Castillo, que no deja de prestar atención a la vida cotidiana y a las menudencias prosaicas de las transacciones necesarias para conseguir alimentos o vivienda, salpica su obra con numerosas anécdotas en las que el lector se asoma a alguna de aquellas dificultades:

Y en aquella sazón quiso Dios que hacía bonanza en aquella costa, lo cual pocas veces suele acaescer. Y como llegamos en tierra, hallamos tres caciques, que el uno dellos era gobernador de Montezuma, y con muchos indios de su servicio. Y tenían allí gallinas de la tierra y pan de maíz, de lo que ellos suelen comer, y frutas que eran piñas y zapotes, que en otras partes llaman a los zapotes mameys. Y estaban debaxo de una sombra de arboles, puestas esteras en el suelo; y allí, por señas, nos mandaron asentar, porque Julianillo, el de la punta de Cotoche, no entendía aquella lengua, que es mexicana; y luego trujeron braseros de barro con ascuas, y nos sahúman con una. (Díaz del Castillo 2011: 58)

Las señas, el lenguaje gestual, la deixis y aun la representación debieron de ser de uso común entre españoles y nativos en los primeros momentos y quizá en tiempos posteriores. Bernal se sirve en este ejemplo de términos que entonces se naturalizaban en lengua española, maíz, mamey, zapote, por ejemplo, pero su interés, quizá no fue el único, lo empuja a discriminar incluso entre variantes de un mismo término. El zapote es voz náhuatl, mientras que el mamey lo es del taíno. Bernal registra

2 (GARGATAGLI 2007). El intérprete Orteguilla no era mexica, sino español. 
la distribución de los usos, aunque parece no darse cuenta de que se trata de lenguas diferentes. Pero, además, el zapote, según el diccionario de la RAE, no es solo un fruto concreto, también es un término genérico para un tipo de frutos, del 'náhuatl tzapotl, cualquier fruto de sabor dulce, aplicado luego al del zapote', de forma que parece como si Bernal hubiera detectado alguna particularidad en el uso de este vocablo. Pero en cuanto se abandona el terreno en el que el referente es tan concreto como un fruto, las cosas son más complejas. Parece razonable pensar que el brasero con ascuas y el sahumerio a que dio ocasión debían de ser parte de alguna clase de rito o ceremonia, pero ahí no acompañaron a Bernal sus conocimientos. El lector, no más que el propio Bernal, se queda sin conocer lo que parece ser una ceremonia de bienvenida.

Era popular, ciertamente, la capacidad de los soldados españoles para propiciar equívocos en los contactos con los nativos. No son pocas las veces en que se hace mención de equivocaciones fundadas en malas interpretaciones o en el desconocimiento. La anécdota de Yucatán, del topónimo de Yucatán, según la cual los soldados que saltan a tierra y preguntan al primer nativo con el que se encuentran que en qué tierra se hallan y oyen decir «Yucatán», que una tradición interpreta como «no entiendo», bautizan este territorio con el nombre de Yucatán. Teniendo en cuenta que es una anécdota que encuentra eco en los escritos de Hernán Cortés no parece descartable que fuera una broma del propio Cortés o que este repitiera una broma que se había popularizado ${ }^{3}$. Pero sin necesidad de acudir a anécdotas, que pudieran parecer dudosas, hay suficientes ejemplos, menos conocidos y por ello mismo acaso más auténticos, en los que los españoles se enfrentan con problemas que creen haber resuelto. Poco después de que los nativos sahumaran a sus invitados, en el texto antes citado de Bernal Díaz del Castillo, llegaron estos a otro lugar en el que entraron en un templo en un isla, en el templo hallaron los restos de dos muchachos sacrificados.

Y el General preguntó al indio Francisco, por mí memorado, y que trujimos del río de Banderas, que parescía algo entendido, que por qué hacían aquello [sahumarlos]. Y esto se lo decía medio por señas, porque entonces no teníamos lengua ninguna, como ya otras veces he dicho, porque Julianillo y Melchorejo no entendían la mexicana. Y respondió, que los de Culúa los mandaban sacrificar; y como era torpe de lengua, decía, «Ulúa, Ulúa»; y como nuestro capitán estaba presente, y se llamaba Juan y era por San Juan de junio, pusimos por nombre a aquella Isleta, San Juan de Ulúa; y este puerto es agora muy nombrado y están hechos en él grandes mamparos para que estén seguros los navíos... (Díaz del Castillo 2011: 62-62)

${ }^{3}$ CORTÉs (1985: 40): “...no sabiendo lo que se decían, la intitularon y llamaron Yucatán, porque los dichos primeros descubridores, como llegasen allá preguntasen a los indios naturales de la dicha tierra que cómo se llamaba aquella tierra, y los indios no entendiendo lo que les preguntaban, respondían en su lenguaje y decían Yucatán, Yucatán, que quiere decir, no entiendo, así los españoles descubridores pensaron que los indios respondían que se llama Yucatán, y en esta manera se quedó impropiamente a aquella tierra este nombre de Yucatán". 
El intérprete tiene que entender a través de señas lo que se le dice. Un enunciado, por cierto, bastante complejo: pedían explicaciones de por qué los sahumaban. $\mathrm{Y}$, aunque este intérprete parece algo entendido, es torpe de lengua. ¿Cómo pudo saber estas cosas Bernal? Los de Culúa, los mexicas, dan involuntariamente nombre al puerto de Veracruz, nombre que hoy sigue ostentando y que se lo dieron entre un capitán cuya onomástica se celebraba ese día, un indio, torpe de lengua, cuya lengua materna era el náhuatl, que no conocía la lengua española, y un español que nada sabía de náhuatl. La combinación era favorable para que este topónimo, quizá como muchos otros, se creara de forma azarosa.

Este desconocimiento, confianza y desinterés no eran privativos de los españoles en el Golfo de México. En un área muy alejada de esta, en Colombia, hay testimonios de que la capacidad de los españoles en materia de conocimiento de lenguas era homogénea y uniformemente deficiente.

Procuró el general de Quesada saber qué gente tenía su contrario: hizo preguntar a algunos indios de la tierra que había cogido por intérpretes de aquel indio que cogieron con los dos panes de sal y los había guiado hasta meterlos en este Reino, que con la comunicación hablaba ya alguna palabras en español; respondieron los preguntados en su lengua diciendo musca puenunga, que es lo propio que decir mucha gente. Los españoles que lo oyeron dijeron: «dicen que son como moscas»; y al describirlos lo confirmaron, y aquí se les pegó este nombre de moscas, que primero se acabarán todos ellos que el nombre. (Rodríguez Freyle 1997: 41)

En este caso, la confusión la propicia la homofonía, pues los muiscas, la etnia con la que se enfrentaban Gonzalo Jiménez de Quesada y los soldados españoles, ciertamente, se conocían a sí mismos como muiscas, voz que en lengua muisca o chibcha quiere decir 'gente', 'personas'. Tanto en este caso, como en el anterior, el hablante español da por hecho que el nativo que lo escucha entiende la lengua española y que la voz muisca no puede ser sino mosca. La semejanza con las acuñaciones de las voces anteriores hace pensar que había un conocimiento más o menos popular de que los españoles improvisaban e inventaban de forma continua.

El propio Hernán Cortés es un buen representante de sus soldados, es un buen representante de quien tiene un interés en la lengua que no va más allá de lo inmediatamente útil. Para él, las lenguas, los intérpretes (los lenguas) y cualesquier hechos relacionados con la comunicación con los que tuviera que habérselas no eran sino medios para lograr sus fines. Aunque no dejaba de llevar a cabo muy refinados análisis de la pragmática de la comunicación, cuando venía al caso, es decir, cuando le interesaba.

Y aunque se les hizo de mal, porque tenían temor que yéndoles con aquel mensaje los matarían, dos de aquellos prisioneros se determinaron de ir, y pidiéronme una carta; y aunque ellos no habían de entender lo que en ella iba, sabían que entre nosotros se acostumbraba, y que llevándolo ellos los de la ciudad les darían crédito. Pero con las lenguas yo les di a entender lo que en la carta decía, que era lo que yo a ellos les había dicho. (Cortés 1985: 213) 
Hernán Cortés accede a cumplir una formalidad en la remisión de la carta, siendo consciente de que su valor comunicativo era nulo, pues nadie podía leerla, porque sus destinatarios no conocían la lengua española, sin embargo, explicó a las prisioneros, a través de los intérpretes, el contenido de la carta. La carta manuscrita deja de tener valor, su contenido es su expresión oral. El valor comunicativo no es el contenido de la carta, las instrucciones o declaraciones, sino el hecho de que la carta misma iba a considerarse, por parte de quienes la recibieran, como testimonio de autenticidad y de autoridad. Los que recibieran la carta sabrían que entre los españoles las cartas que se cruzaban de un lado a otro obraban efectos que eran prueba e instrumento de poder, la presencia de la carta era el testimonio de la autenticidad, la interpretación de los prisioneros comisionados para llevar la carta era el contenido que, una vez aceptada la autoridad, había que acatar o al que había que responder. Hernán Cortés era muy consciente de que el significante iba a determinar la credibilidad de la comunicación, el significante se había convertido en el significado, mientras que el significado de la carta se había transformado en su versión oral.

Pero lo anterior es una excepción. La excepción que muestra cómo para quien desea servirse de la lengua para manipular la comunicación no le es necesario mostrar ningún interés o respeto por la lengua misma. La valoración de Hernán Cortés, también en el terreno de la lengua, es muy pobre. Su interés y conocimientos se han calificado, generalmente, de forma negativa.

La cerrazón al pronunciar las voces indígenas, así como otras tantas cosas, vienen a evidenciar que ya por dentro se encontraba blindado. Nunca llegó a pronunciar correctamente el nombre de Tenochtitlán, el cual escribía de tres maneras diferentes, así como tampoco se pone de acuerdo con el de Motecuhzoma que, de semejante manera, escribe de distintas formas. Si se observa el número de nahuatlismos que emplea, para contarlos sobran los dedos de las manos: tianguez, maceguales, tamemes, calpixques, tequitato... En cuanto al año y medio que pasó en zona de habla maya, durante el viaje a Las Hibueras, no se detecta que se le haya pegado una sola palabra. [Otros vocablos como maíz, cacique, cazabe, canoa procedentes de la lengua taína, formaban ya parte del castellano en los momentos en los que él llegó a las Antillas. En orden de procedencia, canoa viene a ser la primera voz antillana en incorporarse al idioma, ya que Colón la emplea en la carta en la que comunica al tesorero Santángel el Descubrimiento.] Esa dureza de oído pone de manifiesto su escaso interés por la lengua y la religión indígena. Y de igual manera, permaneció totalmente ajeno a la sensibilidad estética del mundo conquistado, lo cual evitó, en buena medida, que se produjese una mezcla de culturas. Lo que a él le interesaba era la creación de un país a imagen y semejanza de España. No resultaría exagerado decir que murió tan español como nació. (Miralles Ostos 2010: 579-580)

Cierto es que el desinterés que se señala podría, además, revestirse de un interés ilegítimo, pues el vocabulario náhuatl del que se sirve Hernán Cortés muestra necesidades fundamentales en el curso de su vida. Los tianguez no son sino 'mercados', 'mercadillos'; los maceguales y tamemes son 'porteadores'; calpixque es un 'capataz que ejerce su autoridad sobre los indios'; y, en fin, el tequitato es también 'quien 
ejerce autoridad sobre los indios'. Bien se ve que el selecto léxico de Hernán Cortés arroja un curioso perfil sobre la persona. Sus intereses, si han de juzgarse a través de este reducido vocabulario, se circunscriben a las necesidades básicas de la manutención y los suministros de bienes, al acarreo de armas o mercancías y al gobierno, en este caso concreto, de la población nativa. No se traen estas consideraciones para censurar a Hernán Cortés, quien, dicho sea de paso, no está precisamente ayuno de condenas y censuras, sino para mostrar un ejemplo que bien pudiera corresponder a más de un compatriota del capitán español. Es representativo, en este sentido, Hernán Cortés de muchos otros soldados, funcionarios o profesionales y artesanos españoles o de otros países de los que llegaron a México.

No ha de pensarse, sin embargo, que del otro lado, del lado de los nativos, las cosas fueran siempre mejores. El prendimiento y muerte de Atahualpa son el resultado del desconocimiento de la pragmática de comunicación de los españoles. Hay muchos otros testimonios:

Consuelo era, aunque triste, para los que después se perdían, en hallar delante compañeros cristianos con que pasar los trabajos y entenderse con aquellos brutos. Muchos españoles escaparon las vidas por hallar delante compañeros cristianos, porque los indios que los tomaban, les mandaban bailar y cantar y no lo entendían; y como los indios son tan bellacos, y más los de la Florida, pensaban que no lo querían hacer por rebeldía; los mataban y decían después a su cacique que por bellacos y rebeldes los mataban, que no querían hacer lo que les mandaban; preguntando el cacique que por qué los mataban, respondían esto que tengo dicho. (Escalante Fontaneda 1866: 542)

Tantas posibilidades tenían los españoles de entender lo que se les decía como los nativos la tenían de entender de buenas a primeras lo que se les decía. La diferencia, en ambos casos, bien podía ser la diferencia entre la vida y la muerte. Los indios que piensan que los españoles que no les responden en su lengua actúan movidos por mala voluntad no se apartan mucho de los españoles que se dirigen a los nativos americanos como si dieran por hecho que habían de hablar su misma lengua.

Los segundos españoles que llegan a México, quizá no en orden cronológico, fueron los religiosos. Segundos porque llegaban detrás de las banderas de los soldados, no porque tardaran más que estos. Son los religiosos quienes dibujan el perfil ideológico de la aventura. Ellos se encargan de poner orden y concierto en lo que, de otra manera, parece inexplicable. Los españoles que se subrogan en la aventura ultramarina, los soldados, son prácticamente los mismos soldados que acaban de conquistar los últimos reductos del reino nazarí, son españoles que conocen las técnicas del asedio y de la toma de ciudades y, por consiguiente, esperan que en un mar que acaban de descubrir no se hallen sino las mismas o parecidas cosas a las que dejaron atrás. ¿Hicieron cosa diferente los clérigos? Sobre ellos recayó la tarea autoimpuesta de conocer las lenguas que se hablaban en América. Se impusieron a sí mismos esta tarea para cumplir con su función de evangelizar. En parte, porque los clérigos, que desconfiaban de sus compatriotas, pensaban que los nativos no deberían aprender la lengua española, pues así se evitaban el riesgo de corromperse como, a su juicio, estaban corrompidos los propios españoles. En parte, para que el 
mensaje del evangelio llegara en la lengua que hablaban. Sin embargo, la única herramienta que tenían para profundizar en el conocimiento de las lenguas americanas era la gramática de Nebrija. Quizá el libro escrito en español del que más ejemplares hubo en tierras americanas en los primeros tiempos fue la gramática de Nebrija, el modelo mediante el que se describieron todas o la mayoría de las lenguas que los religiosos españoles alcanzaron a conocer.

Los soldados, pues, no estaban solos en su desconcierto. Un desconcierto que no se refería de forma única a la traducción y a la descripción lingüística. El desconocimiento tenía otras bases y otras fuentes de inspiración. Bases y fuentes de naturaleza cultural y de explicación histórica. Bernal Díaz del Castillo, por ejemplo, llama siempre a las pirámides, mayas o aztecas, hasta Tenochtitlán, correctamente, cues o adoratorios, no importa que la palabra $c u$ sea maya. Pero Hernán Cortés no está tan seguro de que lo que ve sean cues o adoratorios, para él todo son mezquitas. En Churultecal, el propio Cortés (1985: 105) cuenta «desde una mezquita cuatrocientas treinta y tantas torres y todas son de mezquitas». Pero si los soldados no tenían una idea clara de qué era aquello que iban descubriendo, un día tras otro, los clérigos que los acompañaban no estaban mejor informados. Un referencia erudita a las actividades del teatro catequístico de la época proporciona al lector una clave digna de nota:

En su obra Indios imaginarios e indios reales en los relatos de la conquista de México, Guy Rozat (2002) analiza cómo la historiografía clásica proporcionó modelos para explicar la realidad americana. La destrucción de Tenochtitlán podía entenderse a partir de la destrucción de Jerusalén, y por lo tanto no es extraño que en el teatro catequístico novohispano se encuentre representado este drama, tanto en castellano como en náhuatl, como veremos más adelante. En particular, Beristáin de Souza consigna en su Biblioteca el manuscrito El sitio y destrucción de Jerusalén por Tito y Vespasiano, como traducción al náhuatl de fray Andrés Ubilla, a mediados del siglo XVI. (Payás Puigarnau 2010: 65)

Es desconcertante que de toda la dramaturgia posible a disposición de fray Andrés Ubilla se hubiera elegido precisamente el paralelismo entre la caída de Tenochtitlán y el sitio y destrucción de Jerusalén por parte de Vespasiano y Tito. En contra de la opinión de Gertrudis Payás, sí es extraño este teatro catequístico. La historiografía clásica proporcionaba abundantes ejemplos para explicar la realidad histórica mexicana o la presencia de los españoles en el continente americano. ¿Por qué no se recurrió a los ejemplos de la guerra de las Galias?, ¿a Salustio?, ¿a la guerra de Yugurta?, ¿a Suetonio?, ¿a Tito Livio?, ¿a la propia caída de Roma o a la de Constantinopla? En cuanto a Fray Andrés Ubilla, traductor al náhuatl de la obra dramática manuscrita El sitio y destrucción de Jerusalén por Tito y Vespasiano, ¿qué lo movió a elegir semejante obra?, ¿qué valor instructivo o, específicamente, catequístico pudo pensar que contenía esta obra? No debe olvidarse que se trata de teatro de adoctrinamiento religioso, evangelizador. La respuesta es bien sencilla, pero no es menos sorprendente que la de las opiniones de Hernán Cortés, quien se dedicaba a comparar de forma continua a quienes se encuentra en América con los habitantes del norte de África y con la cultura del islam. Algunos españoles pensaban que los 
habitantes de América eran descendientes de los judíos expulsados por Vespasiano y Tito. Eso explicaba todo. Fray Andrés Ubilla quería provocar, a través de una representación artística, una anamnesis que permitiera a los paganos aceptar su propia realidad histórica y, asimismo, que facilitara la aceptación del valor redentor de la catequesis católica. Fray Andrés venía a decirles que lo que ya les ocurrió una vez, la destrucción de Jerusalén, volvió a ocurrir una segunda vez, la destrucción de Tenochtitlán, precisamente por persistir en sus errores e idolatría. Bernal Díaz del Castillo es uno de los que más tempranamente plantearon en primer lugar el posible origen de la procedencia última de los habitantes de América. «Y como vieron los ídolos de barro y de tantas maneras de figuras, decían que eran de los gentiles. Otros decían que eran de los judíos que desterró Tito y Vespasiano de Jerusalén y que los echó por la mar adelante en ciertos navíos que habían aportado en aquella tierra». (Díaz del CASTILlo 2011: 38). Bernal es siempre, en términos generales, muy preciso. Pero no debe excluirse que pusiera en las primeras páginas de su relato algo que oyera posteriormente. Quienes decían que los indios americanos eran gentiles, paganos, eran, tal vez, todos o los más de los españoles, pero había una opinión de «algunos» que explicaba el origen de los nativos americanos como si fueran descendientes de los judíos expulsados por Vespasiano y Tito. ¿Quienes eran estos algunos? Muy probablemente fueran sacerdotes o clérigos, pues se hace difícil pensar que los soldados tuvieran ni siquiera el conocimiento necesario para expresar una conjetura de semejante índole.

Es interesante considerar que los españoles, si el orden cronológico de Bernal Díaz del Castillo es fiable, ya había decidido que los indios eran descendientes de los judíos expulsados por Tito mucho antes de que aquellos supieran de la existencia de Tenochtitlán. De forma que el simbolismo de la destrucción de Tenochtitlán y el paralelismo con la destrucción de Jerusalén no son sino sobrevenidos. DUPEYRON (2002: 184). «Nos parece que este esquema de la destrucción se aplica perfectamente a la de Tenochtitlán de México. Basta reemplazar judíos por indios, gentiles por cristianos, para que se establezca el mismo esquema de la ruptura». Puede que el simbolismo se explicara tras la caída de Tenochtitlán, que se lo explicaran entre sí los españoles, que se lo explicaran a los supervivientes aztecas, y que tradujeran esas ideas en obras dramáticas como la reseñada anteriormente, El sitio y destrucción de Jerusalén por Tito y Vespasiano, pero ese simbolismo se alza sobre la base de una explicación previa, previa, es decir, previa a la caída de Tenochtitlán, que los españoles habían improvisado para hacer comprensible para ellos el origen de los indios.

Conviene apresurarse a decir, para lavar el honor científico de los españoles, que Joseph de Acosta, en 1590, ya había dado una explicación que es la que comúnmente se acepta como históricamente fidedigna y que no implicaba reconocimiento alguno del origen judío de los indios:

Así que ni hay razón en contrario, ni experiencia que deshaga mi imaginación u opinión, de que toda la tierra se junta y continúa en alguna parte; a lo menos se allega mucho. Si esto es verdad como en efecto me lo parece, fácil respuesta tiene la duda tan difícil que habíamos propuesto, cómo pasaron a las Indias los prime- 
ros pobladores de ellas, porque se ha de decir que pasaron no tanto navegando por mar como caminando por tierra. Y ese camino lo hicieron muy sin pensar mudando sitios y tierras su poco a poco, y unos poblando las ya halladas, otros buscando otras de nuevo, vinieron por discurso de tiempo a henchir las tierras de Indias de tantas naciones y gentes y lenguas. (Acosta 2006: 62-63)

Al menos un español ofreció una explicación a la comunidad científica que no se aparta de lo que hoy es comúnmente aceptado por los estudiosos. Pero la observación de Joseph de Acosta muestra que el problema del origen de los pueblos amerindios atrajo la atención de los españoles en América.

Y no menos conveniente será tener en cuenta que sobre el origen de los pobladores de América corría por Europa toda suerte de teorías. No todas tenían como centro de interés a los judíos. A decir verdad, estos orígenes se diversificaban en función del conocimiento que se poseía de los diferentes pueblos.

Hornius aceptó que la cronología bíblica proporcionaba un marco más allá de cuyas fronteras no podía ir la historia. Pensaba que las gentes del Nuevo Mundo provenían de gentes identificables del Viejo Mundo. Defendía que los salvajes tártaros o escitas y los civilizados chinos eran, los primeros, antepasados de las tribus indias nómadas, mientras que los segundos lo eran de los aztecas y los incas. La conexión entre los bárbaros del Nuevo Mundo y los sabios del Cercano Oriente se estrechó ${ }^{4}$.

Casi parece exclusivamente española la propuesta de que los judíos fueran los antepasados de los indígenas americanos. No debe ni puede pensarse, ni mucho menos, que la explicación de Bernal Díaz del Castillo fuera un hecho aislado o que no la compartiera un grupo de personas especialmente influyente en todos los relatos en los que se registra la llegada de los españoles a América. En Colombia, sin Tenochtitlán que rescatar de la idolatría, un cronista, fray Pedro Simón, desarrolla una completa hipótesis sobre el posible origen de los pobladores de América.

I. Opinión de los indios de estas tierras son originarios de las diez tribus de Israel.- II. Dícese que no son sino de la tribu de Isachar, según una profecía de Jacob.- III. Vase declarando la profecía y aplicando al intento.- IV. Prosíguese en lo mismo. (Simón vol. 1 1882: 23)

Este es el epígrafe del capítulo. He aquí parte del desarrollo de la noticia:

No ha dejado de inclinarme a creer esta opinión más que otras, con su fundamento, y otros que le ponen, y con su modo de pasaje a estas partes; pero con la limi-

\footnotetext{
4 "Hornius assumed that biblical chronology provided a frame beyond the borders of which history could not go. He still believed that the New World peoples derived from identifiable Old World peoples: he canvassed both the wild Tartars, or Scyths, and the civilized Chinese, the former as the ancestors of the nomadic Indian tribes and the latter as those of the Aztecs and Incas. The connection of the New world barbarians and Near East sages became ever closer". (GRAFTON 1992: 235).
} 
tación que diré (con licencia o sin ella de sus autores), fundado en las costumbres y naturaleza que he conocido en estos indios el tiempo que estoy entre ellos, y lo que les ha sucedido en la entrada de los castellanos en sus tierras: y así digo parecerme originarse estos indios de los hijos de Israel; pero no de todas las diez tribus que se perdieron, sino solo de la tribu de Isachar; porque veo cumplida en ellas, cuanto al sentido literal, la profecía que a la hora de su muerte dijo el Patriarca Jacob había de sucederle a esta tribu entre las demás cosas que profetizó a los demás sus hijos: la cual dice así: Isachar assinus fortis accubans inter terminos: vidit requien quod esset bona; et terram, quod optima, et apposuit humerum suum ad portandum, factusque; est tributis servies. Isachar ha de ser un asno fuerte, que ha de estar echado entre términos; vio la holganza que sería buena, y la tierra bonísima; puso su hombro para llevar la carga, y sirvió para pagar tributos. (Simón vol. 1 1882: 24)

La primera edición de las Noticias historiales se registra en Cuenca en 1627. Fray Pedro Simón no solo tiene la certeza de que los nativos americanos descienden de una de las tribus perdidas de Israel, él puede identificar de forma muy precisa de qué tribu de Israel provienen los nativos que son objeto de su interés y descripción. Conviene recordar que en esta ocasión no son Vespasiano y Tito los causantes de la dispersión de los judíos. El episodio al que alude fray Pedro Simón ocurrió en el 722 a. de C. En esta ocasión fue el rey asirio Sargón II el responsable de la expulsión de los judíos. Las diez tribus perdidas fueron las siguientes: Simeón, Dan, Manasés, Isacar, Zabulón, Aser, Neftalí, Rubén, Efraín, Gad y parte de la de Leví. Antonio de Montezinos, explorador portugués, en torno a 1644, fue responsable de divulgar la noticia de que había hallado alguna de las tribus perdidas en lo que vagamente se correspondería al territorio de Colombia, «roughly today's Colombia», Perelis (2004: 195). La noticia alcanzó notoriedad y logró difusión en la judería de Amsterdam, a través de la cual se conoció el hecho y fue debatido en diferentes países europeos. Montezinos se encontró con los descendientes de Rubén: Un «grupo de americanos nativos a quienes identificó como descendientes de la tribu de Rubén». Perelis (2004: 195). Fray Pedro puede reclamar la prioridad en el hallazgo de las tribus perdidas de Israel, también puede enorgullecerse de haber sido capaz de identificar otra tribu concreta, la de Isacar. La posible presencia de los judíos en América y aun las de otros pueblos había sido motivo de reflexión para estudiosos e historiadores desde el siglo XIV.

No debe pensarse que el asunto fue motivo solo de una curiosidad pasajera. No debe pensarse que los presuntos israelitas americanos se olvidaron en cuanto un mejor conocimiento de la historia pudo despejar la tinieblas de desconocimiento. Ha de tenerse en cuenta, además, que muchas de las ideas sobre el origen de los pobladores de América tenían como centro de preocupación el hecho de que, necesariamente, los americanos autóctonos tenían que haber salido del arca de Noé. Cualquier explicación que se diera sobre el posible origen de estos pobladores no podía contradecir este hecho determinante. Popkin (1989: 64): «A principios del siglo XVII varios exploradores españoles y teólogos debatieron sobre el origen de los indios, siempre indicaron que la solución debía tener en cuenta que era preciso seguir su origen hasta la misma Biblia». 
Si los españoles estaban equivocados en sus conjeturas, en su momento, sabiendo lo que sabían, no deja de ser sorprendente que años más tarde un ilustrado, un viajero francés, en pleno siglo XVIII, todavía pudiera expresar juicios de índole histórica que, sin duda, tenían en cuenta las ideas de los españoles en los siglos inmediatamente anteriores:

Palabras hebreas comunes en muchas lenguas de América.-La palabra abbá, babá, o papá, y la de mamá, que de las antiguas lenguas de Oriente parecen haber pasado con ligeros cambios, a la mayor parte de las de Europa, son comunes en un gran número de pueblos de América, cuyo lenguaje es, por lo demás, muy diferente. Si se considera a estas palabras como los primeros sonidos que los niños pueden articular y, por consiguiente, como los que en todos los países han debido ser preferentemente adoptados por los padres que los oían pronunciar para hacerlos servir de expresión a las ideas de padre y de madre, falta saber por qué en todas las lenguas de América en que se encuentran estas palabras se ha conservado sin confusión su significado; por qué casualidad en la lengua Omagua, por ejemplo, en el centro del continente, o en otra cualquier parecida, en que las palabras papá y mamá se usan, no ha sucedido nunca que papá signifique madre, y mamá, padre, sino que constantemente sucede lo contrario, como en las lenguas de Oriente y de Europa. Hay muchas probabilidades de que se encontrarían otros vocablos entre los naturales de América cuya conexión con los de alguna otra lengua del Viejo Mundo podría algún día esclarecer una cuestión abandonada hasta ahora a simples conjeturas (La Condamine 1921: 42)

En 1745 todavía había quien opinaba que no era descartable el posible origen hebreo de los pobladores originales de las tierras americanas.

La historia de la traducción en América quizá no se haya llevado a cabo de forma satisfactoria. Tal vez porque es un fenómeno de una magnitud desmesurada, inabarcable, cuyas consecuencias se ramifican hacia lugares remotos y llegan hasta el presente. Más allá de las denuncias de abusos y de exámenes de las relaciones de poder y de necesarias condenas de las agresiones de toda índole, también deben tenerse en cuenta circunstancias que condicionaron o dificultaron o hicieron imposible la traducción. El conjunto de elementos que debe tenerse en cuenta es mayor del que habitualmente suele considerarse a la hora de hablar de estos fenómenos. Se han señalado dos de estos elementos: la propia condición social e intelectual de quienes llegaron a América y tuvieron que relacionarse, a veces con la urgencia de la vida o la muerte, con los habitantes del continente y las ideas previas que reducían, equivocadamente, lo desconocido a lo conocido. Los elementos dados parece que hacían imposible o muy dificil la traducción y, sin embargo, en las formas parciales y equivocadas que se quiera, no cabe duda de que hubo formas de comunicación y de traducción sorprendentes.

\section{Referencias bibliográficas}

Acosta, J. de., Historia natural y moral de las Indias. Edición de Edmundo O’Gorman. México: Fondo de Cultura Económica 2006. 
Cortés, H., Cartas de relación. Ed. de Mario Hernández. Madrid: Historia 161985.

Díaz del Castillo, B., Historia verdadera de la conquista de la Nueva España, edición de Guillermo Serés. Madrid: Real Academia Española 2011.

Dupeyron, G. R., Indios imaginarios e indios reales en la conquista de México. México: Universidad Veracruzana 2002.

Escalante Fontaneda, H. de, «Memoria de la costa, cosas e indios de La Florida», en: Torres de MendozA, L., Colección de documentos inéditos relativos al descubrimiento, conquista y organización de las antiguas posesiones españolas en América y Oceanía, sacados de los archivos del Reino, y muy especialmente del Indias. Tomo V. Madrid: Imprenta de Frías 1866.

GARGATAGLI, M. «La traducción de América», <http://www.traduccionliteraria.org/1611/art/gargatagli.htm>, 2007, acceso: 14 de abril de 2013.

Grafton, A. / Shelford, A. / Siraisi, N., New Worlds, Ancient Texts: The Power of Traditon and the Shock of Discovery. Cambridge (Massachusetts): The Belknap Press at Harvard University Press 1992.

La Condamine, Ch. M. de, Relación abreviada de un viaje hecho por el interior de la América Meridional. Trad. Federico Ruiz Morcuende. Madrid: Calpe 1921.

Miralles Ostos, J., Hernán Cortés, inventor de México. Barcelona: Tusquets 2002.

Payás Puigarnau, G., El revés del tapiz: Traducción y discurso de identidad en la Nueva España (1521-1821). Madrid: Vervuert - Iberoamericana 2010.

Perelis, R., «These Indians are Jews! Lost Tribes, Crypto Jews, and Jewish Self-Fashioning in Antonio de Montezinos's Relación in 1644», en: Richard, K. L. / Morgan, P. D. (eds.), Atlantic Diasporas: Jews, Conversos, and Crypto-Jews in the Age of Mercarcantilism, 1500-1800. Washington D. C.: Wooodrow Wilson Press 2004.

PopkIN, R. H., «The Rise and Fall of the Jewish Indian Theory», en: KAPLAN, Y. / MÉchoulan, H. / PopkIN, R. H. (eds.), Menasseh ben Israel and His World. Leiden: E. H. Brill 1989.

Rodríguez Freyle, J., El carnero. Ed., introducción y notas de Mario Germán Romero. Santafé de Bogotá: Instituto Caro y Cuervo 1997.

Simón, P., Noticias historiales de las conquistas de Tierra Firme en las Indias Occidentales. 5 vols. Bogotá: Imprenta de Medardo Rivas 1882-1892. 